revista do ieb n 45 p. 141-152 set 2007

\title{
0 universo conceitual de Paul Zumthor no Brasil
}

Jerusa Pires Ferreira ${ }^{1}$

Resumo

Este trabalho pretende oferecer o universo conceitual de Paul Zumthor em perspectiva. Lidando com as idéias de movimento, deslocação e nomadismo, Zumthor enfoca a oralidade e se concentra nos efeitos da presença, do ambiente e do corpo em ação. Ele cria uma concepção singular de performance, conectando memória ao futuro. A irradiação de suas idéias no Brasil se mostra aqui através de muitas e diversas compatibilidades. A segunda parte apresenta na sua ficção um documento que revela como ele seguiu nossa História recente nas incursões que fez em nosso país.

\section{Palavras-chave}

universo conceitual, oralidade, memória, historiografia, experiência brasileira. 
revista do ieb n 45 p. 141-152 set 2007

\title{
Paul Zumthor's conceptual universe in Brazil
}

Jerusa Pires Ferreira

\begin{abstract}
This work intends to offer in perspective Paul Zumthor's conceptual universe. Dealing with the ideas of movement, displacement and nomadism, Zumthor focuses on orality, specially on the effects of presence, ambiance and body in action. He creates a very singular acception of performance, connecting memory to the future. The irradiation of his ideas in Brazil is shown through many and diverse blendings of compatibilities. The second part of the text presents his fiction as a document that reveals how important our recent history is followed by his incursions in our country.
\end{abstract}

Keywords

conceptual universe, orality, memory, historiography, Brazilian experience. 
Desde que encontrei o grosso volume dos Études de poétique médievale ${ }^{2}$, percebi que algo de muito especial acontecia e que teria alguma coisa a ver com o estudo de nossas literaturas populares/orais. 0 texto medieval, muitas vezes aprisionado na área da filologia ou da historiografia mais tradicional, apontava aí para uma poética da voz que, em verdade, se insinuava desde os primeiros trabalhos de Paul Zumthor, permitindo entender fenômenos referentes à recepção, fundamentais para o entendimento mais pleno desses textos.

Meu entusiasmo foi tão grande que lhe escrevi, começando um circuito não-interrompido. Em março de 1977, chegávamos juntos a São Paulo. Ele, como professor visitante, deu curso e dirigiu seminários de pesquisa na Unicamp. Enfocava os "rhétoriqueurs”, poetas áulicos que, no século XV, desenvolveram um coeso e original exercício poético.

Criou-se a oportunidade para uma fecunda discussão sobre o sistema e a margem, o mundo oficial da cultura e o submundo que irrompe nos interstícios. Discutiu-se a festa e, ainda, os ritos obscenos, os ditos jocosos, sua recepção no universo da corte. Pouco tempo depois, ele publicaria Le masque et la lumière ${ }^{3}$, um dos seus mais fascinantes trabalhos, em que liga a aventura de criação desses poetas às razões e princípios de um século. Neles, figuram a descoberta da América e o enraizamento de futuras utopias.

Depois dessa primeira visita ao Brasil, Zumthor passa a se dedicar com insistência às literaturas orais, com a bagagem de um medievalista, mas contando agora com o laboratório vivo de nossa cultura tão fortemente oralizada, com os textos de poetas populares, cuja atuação era possível seguir de perto, com a riqueza e a extensão de nossa literatura de cordel.

Veio com sua mulher, a medievalista Marie Louise Ollier, para a Bahia, ávido de visitar o sertão onde nasci, Feira de Santana, a fazenda Paus Altos, onde esteve por alguns dias. Intensifica então o percurso pela cultura sertaneja, busca o entendimento de criações que assentam num grande lastro comum, naquilo que denominou "metaconhecimento poético".

Estavam a caminho formulações básicas para um campo de atuação que, a partir dele, se firmou em dimensão universal: o dos estudos das poéticas da oralidade. A noção de movência do texto oral, a ênfase na transmissão da força energética e teatralizante que ele assumiu como "performance", no sentido bem definido de "texto

2 ZUMTHOR, Paul. Études de poétique médievale. Paris: Seuil, 1972.

3 ZUMTHOR, Paul. Le masque et la lumière. Paris: Seuil, 1978. 
em presença”, e a ampliação do próprio conceito de texto e de literatura foram indispensáveis para se pensar nas poéticas da voz.

Apontando para diferentes graus do escrito/oral e modos de ser do texto oral, em trabalhos como o bem conhecido $L a$ permanencia de la voz ${ }^{4}$, Zumthor seria aproximado naturalmente dos chamados oralistas, como Walter Ong e Ruth Finnegan, entre outros, de quem tanto se aproxima quanto se afasta. Inquieto, seria incapaz de permanecer numa direção única: apostava na dinâmica interna do texto e das energias que o movem, e que terminam por fazer dele, como bem disse, "uma epifania da voz".

Introduction à la poésie orale ${ }^{5}$, de que estamos preparando nova edição, é um livro que provém desta experiência no Brasil, conforme declarou em muitas de suas entrevistas. Aí se concentra todo um chão de vivências, a experiência vital e humana de um pesquisador que correu o mundo e reuniu materiais, valorizandoos e, sobretudo, convertendo-se ao "outro", para poder teorizar.

Poderíamos até glosar, dizendo-nos diante de uma "semiose" participante. Nada lhe escapa: das línguas distantes e em extinção (aliás, um tema obsessivo em sua obra mais recente), cuja voz ainda ressoa, às apresentações de roqueiros da década de 1970.

Em julho de 1993, hospedado em nossa casa em Salvador, interessavam-lhe os ruídos do bairro popular, os tambores do Olodum e o disco Parabolicamará de Gilberto Gil, que ouvia repetidas vezes, encontrando aí alguns fios para completar sua trama reflexiva sobre a linguagem.

A letra e a $v o z^{6}$ é um livro notável, espécie de síntese e de ponto de chegada que permite situar a riqueza do universo conceitual de Zumthor. Traz a confirmação de alguns pontos de vista, construídos a partir de trabalhos anteriores. Aí se reúnem o pesquisador arrojado, a erudição espantosa e uma sensibilidade de poeta, os desafios que nos situam em posição de ver com clareza aquilo que parecia impossível não ter sido pensado antes. Quebram-se limites e somos tomados por uma imperiosa necessidade de revisão de algumas de nossas idéias.

Preocupado também com a memória e sua contraparte inclusiva, o esquecimento, o medievalista escreveu alguns textos fundamentais, como "A tradição e o esquecimento", que apresentou num seminário original, Politicas do esquecimento ${ }^{7}$. Neste, dialogando com Iuri Lotman e Jean-Pierre Vernant, assenta suas idéias no eixo tradição/transmissão.

4 ZUMTHOR, Paul. La permanencia de la voz. El Correo Unesco, Paris, n. 8, ago. 1985.

5 ZUMTHOR, Paul. Introduction à la poésie orale. Paris: Seuil, 1983.

6 ZUMTHOR, Paul. A letra e a voz. São Paulo: Companhia das Letras, 1993.

7 ZUMTHOR, Paul. L'oubli et la tradition. Paris: Seuil, 1988. 
Aliás, foi nessa direção que concedeu uma de suas mais belas entrevistas ${ }^{8}$. Ao tempo em que buscava a diversidade, perseguia uma grande matriz de linguagem e pensamento, espécie de antídoto à dispersão, apesar da desejada presença da diversidade.

Trabalhando em várias frentes e voltado para essas questões, não pôde concluir o livro Babel ou l'inachèvement ${ }^{9}$, publicado postumamente. Aliás, sabemos que o tema o perseguia, pois ainda bem jovem tinha escrito uma novela, $O$ poço de Babel, poço e torre antípodas e coincidentes.

La mesure du monde $e^{10}$, ainda não traduzido entre nós, é um livro alentado em que, relacionando tempo/espaço/cultura, Zumthor retoma o alcance mais pleno de sua cogitação sobre o imaginário medieval em sua materialização e ambiência.

0 interessante é que, vivendo nas mais diversas partes do mundo, procurando sempre se integrar, trazia presente a idéia de uma pátria perdida. E então a Suiça parece ter marcado, cada vez mais, sua presença: seu lugar de origem, na grande viagem que empreendeu pelo mundo. Cogitando sobre as relações entre ciência e magia, confessou-me o prazer de iniciar uma extensa pesquisa, reunindo materiais para, no futuro, escrever uma biografia de Paracelso, também suíço. No entanto, não chegou a desenvolvê-la.

Profuso, múltiplo, atuante, creio que sua energia vital e criadora deve permanecer em muitos de nós, que com ele nos relacionamos intensamente. Polígrafo, escreveu mais do que ninguém para falar da voz e de sistemas e linguagens a ela conjugadas, legando-nos uma visada que nos faz passar pelas mediatizações, alcançar a força do corpo e dos sentidos, afirmação inequívoca e perene do humano.

Temos em Introdução à poesia oral ${ }^{11}$ uma ampla recolha e um reconhecimento que contribuem para o entendimento dos "gêneros" (conceito que incomodava Zumthor) e das possibilidades de expressão e realização da poesia oral. Mais do que isso, trata-se de um questionamento sobre voz e corpo: uma plataforma e um método de trabalho, a rejeição de certezas absolutas e a proposta de uma espécie de colagem de encontros, achados, desvios que, em vez de provas, querem sugerir e poetizar. Esse livro é ainda um livro sobre os paradoxos da voz, da voz que desborda e ultrapassa toda palavra.

8 Cf. ZUMTHOR, Paul. Poesia, tradição e esquecimento. Folha de São Paulo, São Paulo, 17 set. 1988. Caderno Folhetim, n. 622. (Entrevista).

9 ZUMTHOR, Paul. Babel ou l'inachèvement. Paris: Seuil, 1997.

10 ZUMTHOR, Paul. La mesure du monde. Paris: Seuil, 1993.

11 ZUMTHOR, Paul. Introduction à la poésie orale. Paris: Seuil, 1983; tradução brasileira: ZUMTHOR, Paul. Introdução à poesia oral. Tradução de Jerusa Pires Ferreira et al. São Paulo: Hucitec, EDUC, 1997. 
0 medievalista/poeta pretende arquivar os procedimentos de certa "arqueologia textual", rotuladora e antiquada, e tenta avançar, no sentido de destruir os limites cristalizados, colocando por terra muitos dos preconceitos que sempre estiveram presentes na historiografia da literatura ocidental. É uma questão de postura. Amplia a noção de texto literário, procedendo a uma grande síntese e depois à crítica de algumas das mais importantes teorias contemporâneas, como a estética da recepção. Passando pelos aportes de McLuhan, o texto quer dizer muito mais e compreende desde a parte física de sua emissão até o espaço material e corpóreo de sua realização íntegra e de sua acolhida. Conforme nos diz Zumthor, o texto se tece na trama das relações humanas múltiplas e que, sem dúvida, na experiência vivida foram tão discordantes quanto contraditórias.

Muito importante, em se tratando de oralidade, é acompanhar a relação contínua, e em vários graus, com a escritura, que se destaca no conjunto de sua obra. Pode-se perceber aí o complexo deslinde de formas e técnicas, aquilo que se avalia, a partir do que ocorre com a formulação de itens como "As maneiras de ler" ou "A voz do escrito". Paul Zumthor deixa-nos aberta uma via em que se recupera um mundo de conhecimentos, para o situar, relacionando sempre o passado com o futuro, numa aproximação que se dirige à pluralidade das maneiras de expressar, mas também a uma espécie de continuidade do poético.

Em 1993, ocasião em que visitou novamente a Bahia, saiu no Brasil o seu livro A letra e a voz ${ }^{12}$, que é, de fato, referência indispensável no campo de estudos que trilhamos.

Poderíamos dizer que o antes mencionado Introdução ḋ poesia oral, publicado na França em 1983 e traduzido no Brasil em 1997, tem um forte assentamento no sertão da Bahia, em Feira de Santana, e está ligado à primeira viagem de Zumthor a essas paragens. Trata-se de um livro extraordinário, que situa em sua introdução, como no capítulo conclusivo, a memória, a voz e as ações transmissivas. Considera que a humanidade inteira ficará "despossuída" de sua memória, quando um último índio de determinada tribo se calar. Manifesta sua posição de revolta contra a massificação e o extermínio de populações e de culturas. Nas páginas vibrantes de sua conclusão, ao levar em conta o controle hegemônico dos povos e de sua criação cultural, sugere que nos resta sabotar (sic), criar um respiradouro no cimento em vias de secar ou jogar areia na fechadura, para garantir a vida, as pulsões que emanam do corpo em sua plenitude, nas poéticas da oralidade.

Poderíamos afirmar que sua obra de teórico, pensador, poeta se re-definiu por um conhecimento direto do Brasil e da 
África, pela década de 1980, quando passou a valorizar, ainda mais, todo um contingente vital e transformador das poéticas orais, e a distinguir insistentemente tradição e transmissão, oralidade e vocalidade, contemplando os diversos níveis de mediação.

o Brasil comparece também e de vários modos em sua obra de ficção. Além de teórico e poeta, o ficcionista publicaria, na década de 1990, um livro de contos/novelas: La porte à cotée que tem como capa a porta da igreja de São Francisco, em João Pessoa. Nesse volume, um dos contos nos faz contemplar a Ladeira da Conceição, a Igreja da Conceição da Praia, tendo como personagem um cantador nordestino, que ali vive com sua família.

Em 1997, organizamos na PUC de São Paulo um Colóquio em homenagem a Paul Zumthor, para discutir tópicos e temas de sua obra. Foi publicado como Oralidade em tempo e espaço ${ }^{14}$.

Na seqüência da divulgação e discussão crítica da obra notável do medievalista e estudioso das culturas, traduzimos também, entre outros, o livro Performance, recepção, leitura ${ }^{15}$. Transmite, de modo direto, prático e consistente, algumas das noções e conceitos semeados pelo autor ao longo de sua obra, inclusive o de performance, numa acepção muito sua. Considerando a recepção, a poesia oral e o texto impresso, diz-nos:

A performance e o conhecimento daquilo que se transmite estão ligados. A performance, de qualquer jeito, modifica o conhecimento. Ela não é simplesmente um meio de comunicação: comunicando ela o marca. (Ibidem)

Nesta, como em outras passagens, as dimensões antropológicas, comunicativas, estéticas e cognitivas são trazidas com clareza e acompanhadas de profunda intuição poética, por parte de quem acredita como poucos que "o saber é um longo, lento sabor".

A descoberta da cultura brasileira o engajou a estudar os nossos textos orais, a ler literatura de folhetos (cordel) recorrendo à sua bagagem de medievalista para compreendê-la. Mas, reciprocamente se afastando de atitudes eurocentristas, buscava imersão nesse mundo novo, pleno de energia e de vida. Zumthor os inseria assim no seu universo de prazer, como nos diz depois, para constituir a sua ebriografia de saber e do prazer do texto, combinando afinidades com as formulações de Roland Barthes,

13 ZUMTHOR, Paul. La porte à coté. Montréal: Héxagone, 1994.

14 FEREIRA, Jerusa Pires (Org.). Oralidade em tempo e espaço: colóquio Paul Zumthor. São Paulo: Educ, Fapesp, 1999.

15 ZUMTHOR, Paul. Performance, recepção, leitura. 2. ed. São Paulo: Cosac Naify, 2007. p. 32. 
conforme indica em Parler du Moyen Âge ${ }^{16}$. Ele não cessou de investir na aprendizagem do novo, na observação dos traços específicos de cada cultura.

Tudo isso só fez reforçar os laços de Zumthor com o Brasil. Desde então, interessou-se, por exemplo, pela obra de Caetano Veloso, um dos nossos grandes poetas a que faz referência mais de uma vez em seus textos, e pelas vanguardas artísticas (em particular pelos poetas concretistas brasileiros, Haroldo e Augusto de Campos).

Além disso, sempre atento à nossa história e às culturas tradicionais mais afastadas, aos nossos movimentos rebeldes como o de Canudos, Paul Zumthor visitou na Bahia a cidade de Feira de Santana, começo do sertão. Sem dúvida, nesse momento emergiram para ele algumas das reflexões e das formulações fundamentais para as poéticas da oralidade, da voz e dos públicos populares.

Do ponto de vista da cultura brasileira, há outra obra sua que nos toca diretamente: a bela tese de doutorado, defendida em Genebra em 1943, Merlin: o profeta ${ }^{17}$. Trabalho pioneiro, é uma importante contribuição que fornece subsídios para os estudos brasileiros do sertão, no que toca à profecia e à voz profética. Nessa tese, Paul Zumthor estuda as diversas versões da lenda de Merlin e suas estratégias literárias e políticas. Mostra em Merlin uma voz que se aproxima tanto dos jogos espirituais quanto de uma literatura de combate, na medida em que o encantador oferece, ao mesmo tempo, tanto a promessa de uma vitória a partir das provas do presente, quanto a expressão de uma ordem predeterminada providencial dos acontecimentos da história humana.

La mesure du monde e La traversée são obras que nos importam enormemente do ponto de vista dos espaços e das temáticas americanas ${ }^{18}$. Escrevi, portanto, o posfácio da edição brasileira de A letra e a voz, bem como um texto para nossa edição de Introdução à poesia oral, nos quais tento apresentar algumas temáticas centrais e proposições abertas pela leitura dos livros ${ }^{19}$.

Da formalização do conceito de tradição à verificação de operações dos textos orais em regime de transmissão (incluindo

16 ZUMTHOR, Paul. Parler du Moyen Âge. Paris: Minuit, 1980.

17 ZUMTHOR, Paul. Merlin le prophète: un thème de la littérature polémique, de l'historiographie et des romans. Lausanne: Payot, 1943; reimpresso com um novo prefácio, Genève: Slatkine, 1973.

18 ZUMTHOR, Paul. La mesure du monde. Paris: Seuil, 1993; ZUMTHOR, Paul. La traversée. Montréal: Éditions de l'Hexagone, 1991.

19 FERREIRA, Jerusa Pires. Posfácio. In: ZUMTHOR, Paul. A letra e a voz. São Paulo: Companhia das Letras, 1993. p. 287-296; FERREIRA, Jerusa Pires. Posfácio. In: ZUMTHOR, Paul. Introdução à poesia oral. São Paulo: Hucitec, 1997. p. 301-308. 
aí os aspectos próprios da vocalidade), poderíamos dizer que Paul Zumthor construiu um território inteiramente novo para o campo de nossos estudos. Apoiando-se em sua fabulosa erudição, criou uma espécie de prestígio conceitual para a voz e para o corpo, partindo das imaginadas performances medievais. Foi todo esse trabalho considerável que teve a repercussão possível no Brasil.

Em sua condição de medievalista, ele se abria sempre ao mundo contemporâneo e foi assim que se interessou, por exemplo, pelos grupos de poesia oral e partilhou com o jovem Philadelpho Menezes conquistas da chamada poesia sonora. Em razão de tudo isso, se ele aparentemente se dispersou pelo mundo, voltou-se amorosamente para cada região, procurou inscrever-se no meio dos outros, inscrevendo-os, aos outros, em si.

Eis um exemplo dos domínios de repercussão de seus estudos entre nós, não apenas aqueles que meus colegas e eu dirigimos na universidade. Mas outros há em que podemos acompanhar como ele recusou o cientificismo determinista, os limites rígidos das disciplinas, os saberes restritos a um círculo excessivamente acadêmico e institucional. A criação de novos espaços e a tomada em consideração da força do corpo e das novas instâncias da vida social nos tocaram sobremaneira. Ele pôde realizar sua pesquisa amorosa da América e da África, uma forma diferente de fazer política, oferecendo-nos aquilo de que tínhamos necessidade para estabelecer um grande diálogo e, pelo visto, ajudando-nos a avançar na construção de nossa própria história.

A força e as condições da cultura brasileira na qual a comunicação oral desempenha um papel tão importante mereceram de sua parte mais que uma adesão: ele aproveitou essa oportunidade para aí inserir outras temporalidades. De nossa parte, ocupamo-nos de traduzir e de disponibilizar na medida do possivel a discussão e a circulação de seus textos, sua proposta de pensar a história de forma viva, na sucessão e no cruzamento de acontecimentos propícios a novos olhares.

Os conceitos de Paul Zumthor irradiaram pelo Brasil, do sertão à Amazônia, alcançando públicos universitários e outros, através de diversos intérpretes. Essa qualidade extraordinária de proceder à inscrição do poético no conceito e na erudição rigorosos, sem cessar, e a abertura de uma auto-referência crítica foram verdadeiramente decisivas para nós e apontam novos caminhos, que ele nos motiva e permite explorar.

\section{Paul Zumthor em Tocantins}

Para fazer clara esta relação de textos e idéias, permitome passar por alguns pequenos acontecimentos. Eles me parecem 
particularmente exemplares de um duplo movimento: a curiosidade de Paul Zumthor pelas nossas coisas e a ressonância de seus trabalhos entre nós. Conto também com algumas agradáveis coincidências.

Um dia, por ocasião de uma de minhas visitas ao Brasil Central, após conferência que fiz na Universidade de Mato Grosso, uma jovem senhora se aproximou de mim e me disse que trabalhava na universidade de Palmas-Tocantins e que, para ela e seus colegas, Paul Zumthor e alguns de seus conceitos representavam uma importante descoberta, uma ferramenta de trabalho considerável, que até poderíamos dizer indispensável. De repente, comecei a repetir aquela sonoridade musical e rítmica própria do verso em português, uma redondilha maior: PAUL ZUMTHOR EM TOCANTINS. Do mesmo modo o desempenho sonoro dessas palavras mostrava a harmonia desse encontro entre um mestre europeu e um território afastado do Brasil. Guardei esse episódio como a marca de uma poderosa compatibilidade, de uma troca feliz entre Paul Zumthor e a cultura brasileira.

Gostaria, em seguida, de destacar outra coincidência, que pode parecer mágica. Por acaso, no mês de abril de 2005, em casa de um amigo em Montreal, deparei com um livro de Paul Zumthor. Tratava-se das novelas Les contrebandiers ${ }^{20}$, e eis que constato a presença de referências históricas importantes, no seio desse corpo de ficção, sob a forma de um diário, datado de 24 de outubro de 1988:

São cinco ou seis homens em círculo, ao redor de Rafael, que segura seu radinho de pilha sobre os joelhos. Rafael tem projetos. Ele não vai mofar aqui. Do outro lado da serra, um novo Estado será criado, chama-se Tocantins. Haverá trabalho a fazer, dinheiro. Em Porto Nacional... Rafael segue as notícias. Talvez sua oportunidade. $^{21}$

Paul Zumthor introduz seu personagem e em seu texto nos coloca diante da fundação de um futuro estado brasileiro, o do Tocantins: nossa história política vai ao encontro de seu imaginário no cadinho de uma poética. Passamos também a constatar que ele viveu intensamente o ambiente da promulgação de nossa Constituição democrática de 1988, um fato memorável, e vamos encontrar aí referências ao 15 de novembro, data comemorativa da república brasileira.

20 ZUMTHOR, Paul. Les contrebandiers. Montreal: l'Hexagone, 1989.

21 ZUMTHOR, Paul. Les contrebandiers. Montreal: l'Hexagone, 1989. p. 44. tradução minha. 
E é no belo Prefácio de seu livro que ele nos diz:

0 acaso fez de mim um homem de fronteiras. Eu nasci, bem, há não poucos anos, a alguns quilômetros de uma entre algumas. Mas o que conta muito mais foi o número delas que eu secretamente atravessei ao longo desses anos. Fronteira, limite e separação; traço que demarca para cada um de nós o seu lugar e designa o domínio do Outro: no tempo, não menos que no espaço. ${ }^{22}$

Essa formulação nos conduz ao entendimento do espírito aberto e curioso de Zumthor, desejoso de perceber, para além das fronteiras, a experiência dos homens e a possibilidade de se pôr em contato com a profundeza das singularidades de cada um, recebendo como contraparte, em condições boas ou más, a força daqueles que transforma em seus personagens.

Fora do convencional, despojando-se de idéias desgastadas, coloca em cena os momentos da vida, as condições sociais, as ambições políticas, trazendo observações agudas sobre as pessoas, sobre o ambiente, o destino precário e o extermínio de nossas tribos indígenas. Suas observações são sempre penetrantes, apoiando-se em pequenos fatos ou em anotações breves, para evocar o destino de todo um povo e os caminhos de sua história. Trata-se aí de uma conjunção do seu lado historiador com o observador etnográfico e o ficcionista, sob a vigilância cuidadosa do poeta: atento ao inesperado dos acontecimentos e escutando sua ressonância no conjunto de uma época.

Esse seu livro de ficção/documento nos remete ao dia 10 de outubro de 1988, às 6 horas da manhã, na localidade de Serrabuna, estado da Bahia, a 500 km NE de Brasília: ele vai observando nas camisetas vestidas pelos meninos as inscrições "Universidade Federal" ou "Nossa Senhora da Conceição" e falanos dos donos das terras em que aquela gente vive. Destaca o caso de um desses "coronéis": os meninos lhe contaram só tê-lo visto uma vez havia três anos, quando fôra candidato à eleição. E o seu comentário se faz seguir: "isto é tão distante, frio, desprovido de sentido". Ele procede a uma captação sonora do ambiente, em que se fazem também presentes ruídos e vozes.

Mas o que impressiona é o ponto de partida: um índio que pela primeira vez ouvia os brancos e a dona de casa Serafina que, na juventude, teria sido mulher do último cangaceiro da região (!).

Em 15 de outubro, ele nos diz que os awa são os últimos povos nômades. Sua existência é fugir, esconder-se, reaparecer de improviso e fugir ainda. A reserva awa, pensa o personagem

22 ZUMTHOR, Paul. Les contrebandiers. Montreal: l'Hexagone, 1989. p. 7. 
Joaquim, é a savana deserta que se estende do rio Tocantins ao Araguaia, até os pântanos do Bananal, isto até 500 ou 600 kilômetros daqui, como acreditar?

E Paul Zumthor nos convida a acompanhar o mundo através do radinho de Rafael, seu tesouro, e para nós todos o laço que nos liga aos outros, lá sabe o diabo onde. E é o personagem índio desgarrado que escuta os brancos e vê o rádio como se o espírito falasse numa caixa, à maneira dos brancos. Comenta em seguida o debate entre candidatos ao governo do futuro estado de Tocantins, sobre a escolha de sua futura capital.

Refere-se ainda à existência, por aquela altura, de um plano de extensão do sistema hidroelétrico de Furnas. Comenta que prevêem inundação na área de onde, segundo presume a Funai, se retiravam os últimos sobreviventes livres do povo awa. Seis dentre eles tinham sido encontrados pelos homens da Funai em 1973.

Uma carta dirigida em 1985 pela direção da Funai à Eletrobrás pedia medidas para a salvaguarda daquelas populações nômades. Conta também (através dos apontamentos de Edson Carvalho) que os arquivos do escritório da Funai não tinham registrado resposta.

Parece-me fascinante que esse homem, escrevendo ficção numa viagem a partir de Brasília, se preocupe e registre tudo isso. E que, descrevendo, passando informações, apresentando um casal de etnólogos, o maranhense Edson Carvalho e sua mulher, fazendo do índio awa seu personagem central, consiga um nível de revelação, de poeticidade para nos falar da poeira, do pôr-do-sol ou da paisagem. E citando Clarice Lispector, consegue situar-nos no corpo de um grande silêncio visual, desolação que nos atinge.

Buscou, com efeito, a criação de verdadeiras clareiras conceituais, nichos para pensar questões singulares, laboratórios de experimentação pertinente para se aproximar dos fatos culturais que pôde observar.

Nesse sentido, é preciso dizer que Paul Zumthor foi um pesquisador que não recebia imposições de sistemas fechados, para ele tudo era experimentação e travessia. Se de um lado se concentrava sobre o núcleo da tradição cultural européia, ao mesmo tempo conduzia sua atenção para a descoberta dos novos mundos, das novas modalidades de comunicação, empenhavase na escuta do outro, que afinal não era tão outro assim, e se engajava na crítica das práticas culturais e no entendimento das relações humanas. Por isso, Zumthor dá tanto lugar à memória dessas comunidades, cujas culturas estão em vias de desaparição, ou em transformação, cujas vozes podem calar-se. 